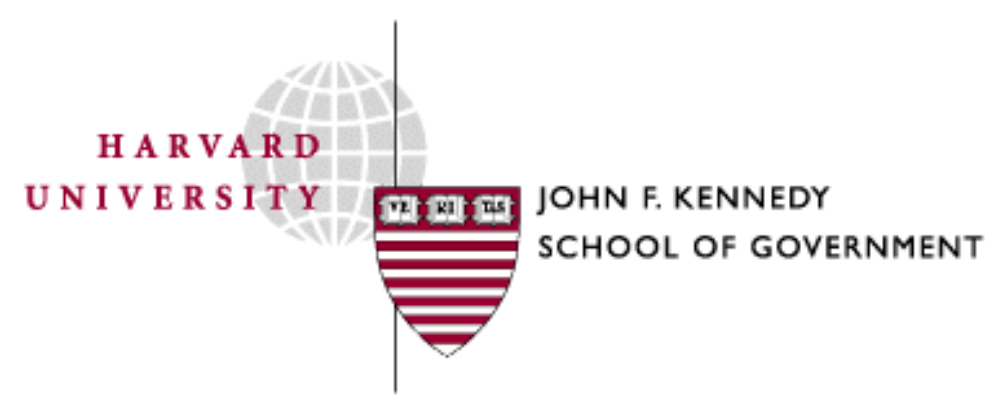

Faculty Research Working Papers Series

Recommendations for the Design of the Federal Docket Management System

Cary Coglianese, Stuart Shapiro, and Steven Balla

November 2004

RWP04-050 belongs to the author(s). Papers may be downloaded for personal use only. 


\title{
Recommendations for the Design of the Federal Docket Management System
}

\author{
Cary Coglianese \\ Regulatory Policy Program \\ John F. Kennedy School of Government \\ Harvard University \\ 79 John F. Kennedy Street, Weil Hall \\ Cambridge, MA 02138 \\ cary_coglianese@harvard.edu
}

\author{
Stuart Shapiro \\ Edward J. Bloustein School of Planning and Public Policy \\ Rutgers, The State University of New Jersey \\ 33 Livingston Avenue \\ New Brunswick, NJ 08901 \\ stuartsh@rci.rutgers.edu
}

Steven J. Balla

Department of Political Science

The George Washington University

401C Old Main

1922 F Street, NW

Washington, DC 20052

sballa@gwu.edu 


\title{
Recommendations for the Design of the Federal Docket Management System
}

\author{
Cary Coglianese \\ Harvard University \\ Stuart Shapiro \\ Rutgers University \\ Steven Balla \\ George Washington University
}

\begin{abstract}
In recent years, regulatory agencies, Congress, and the White House have taken steps to increase the use of information technology in the management of the rulemaking process. The latest such "e-rulemaking" effort is the design of a new, government-wide regulatory information system being developed by Bush Administration. The system, known as the Federal Docket Management System, will for the first time make all information pertaining to federal regulation available to the public via the Internet.

By making information about government regulation available on-line, the Administration's eRulemaking Initiative seeks to improve the quality and legitimacy of the government's regulatory decisions. If developed properly, the Initiative's new online docket management system can also facilitate academic research that in the longer term should improve regulatory policymaking.

The recommendations in this paper, joined by a group of fifty-five other scholars of regulation, were originally delivered in a letter to the Office of Management and Budget, which is spearheading the Administration's eRulemaking Initiative. The paper describes the information currently maintained by government agencies and emphasizes the importance of ensuring that no loss of information occurs in making the transition to the on-line system. It also offers steps that the Administration should take to ensure a high level of quality of the information stored in the new system as well as effective search and downloading capabilities.
\end{abstract}




\title{
Recommendations for the Design of the Federal Docket Management System*
}

\author{
Cary Coglianese \\ Harvard University \\ Stuart Shapiro \\ Rutgers University \\ Steven Balla \\ George Washington University
}

The Administration's eRulemaking Initiative will have important implications for access to regulatory information both for those who work on rules and those organizations and citizens who are affected by rules. We write as scholars of rulemaking to suggest priorities that should guide the eRulemaking Initiative so that all interested parties can better understand and contribute to this common and important mode of policymaking.

Collectively, we have studied rulemaking at dozens of regulatory agencies across the federal government. Based on our extensive experience using agencies' rulemaking dockets and accessing information from them for our research, we believe three

\footnotetext{
* This paper originally took the form of a letter sent November 11, 2004 to the Hon. Karen S. Evans, Administrator of the Office of Electronic Government and Information Technology, and to the Hon. John D. Graham, Administrator of the Office of Information and Regulatory Affairs, Office of the Management and Budget. The authors of this paper were joined on their letter by the following scholars as additional signatories: Richard N. L. Andrews, Michael Asimow, Bernard W. Bell, Lori Snyder Bennear, Barbara H. Brandon, John Brehm, Gary Bryner, Johnny C. Burris, Mariano-Florentino Cuéllar, Steven P. Croley, David M. Driesen, Daniel C. Esty, Victor B. Flatt, William F. Funk, Scott Furlong, Ted Gayer, Marissa Martino Golden, William T. Gormley, Jr., Robert W. Hahn, James T. Hamilton, Michael Herz, William W. Hogan, William S. Jordan, III, Cornelius M. Kerwin, George Krause, David Lazer, Jeffrey S. Lubbers, Gary Marchant, Jerry L. Mashaw, Peter J. May, Kenneth J. Meier, R. Shep Melnick, John Mendeloff, Joel A. Mintz, Beth Simone Noveck, Craig N. Oren, Henry H. Perritt, Jr., Matthew Potoski, Richard J. Pierce, Jr., David H. Rosenbloom, Thomas O. Sargentich, John Scholz, Peter H. Schuck, Peter Shane, Charles R. Shipan, Stuart W. Shulman, David B. Spence, Robert N. Stavins, Peter L. Strauss, Barton H. Thompson, Jr., Robert R.M. Verchick, David Vogel, Jonathan B. Wiener, William West, B. Dan Wood. A copy of the letter is available at: http://ksghome.harvard.edu/ CCoglianese/ScholarLetteronFedDktMgtSystem.pdf.
} 
principles are vital in designing the forthcoming Federal Docket Management System (FDMS):

- Consistency in Data. Every effort should be made to keep data fields consistent, both across agencies and over time. Consistency over time is especially important, so that information available in a post-Regulations. Gov era can be matched with earlier information.

- Flexibility of Search - Users should be able to define their own searches using any of the fields within the docket system. They should also be able to combine different fields.

- Ease of Access - Users should be able not only to search docket data in a selfdefined way, but should be able to download and export search results in commonly used formats, such as comma-separated or Excel or both.

Adherence to these three principles will make it easier for researchers and other members of the public to follow, understand, and contribute to the rulemaking process. Using these principles to guide the FDMS will advance the eRulemaking Initiative's goal of making the regulatory process more transparent to the American public.

In addition to these principles, we offer several specific recommendations about the design, data, and downloading features of the FDMS. Our recommendations are divided into three parts. In Part I, we address the relationship between individual agency dockets and Federal Register documents. The Federal Register is the publication of record for regulatory policymaking and the relationship between individual dockets and 
specific Federal Register notices must be made clear in the new FDMS. In Part II, we enumerate the specific data fields that the FDMS should contain. We believe that important progress can be made with little effort by beginning with data currently reported by agencies as part of the Unified Agenda, Federal Register, and OMB's 83-R Form. Building existing reported data into the online docket system should be readily feasible, as it does not require agencies to report any new data. Finally, in Part III, we discuss in detail the kind of search and download capabilities that should be part of the FDMS. In each Part, we offer specific recommendations to the Administration as it goes forward to develop the new government-wide docket system.

\section{Dockets and Federal Register Notices}

To make the information in the online docket system useful to researchers who study rulemaking, care will need to be given to matching dockets with the Federal Register notices that agencies use to announce their rulemaking activities. This need arises because the way that dockets are used, as well as the type of information they contain, varies markedly across different agencies. Although individual dockets are closely related to individual rulemakings, the correspondence is not always one to one. Some dockets are opened for proceedings other than rulemakings. Some dockets are opened for rulemakings that are later abandoned. Some provide supporting documents for more than one rule. Sometimes agencies have multiple dockets for the same rulemaking (such as when an agency opens a new docket for addressing a petition for an amendment or reconsideration of a rule). 
For researchers who study rulemaking, the relationship between dockets and rules needs to be clearly delineated and consistently treated. There are at least two main ways to address this issue: (1) create a system that allows for varied uses of dockets but still clearly links rules with associated dockets; or (2) require a strict one-to-one relationship between each rule and a corresponding docket. The latter should be feasible if the data in each docket are completely digitized, as it would be just a matter of copying all the pertinent records (even if they were previously in another docket) into the new docket. No matter how the connections between dockets and rules are made, it should be possible for researchers to search the online docket by Federal Register notices and identify the pertinent information from the supporting docket for each proposed or final rulemaking.

Recommendation: The designers of the new government-wide online docket system should recognize that currently not every docket corresponds to a separate rulemaking. Recognizing this fact, the system should be designed to allow users to search the system according to documents filed in the Federal Register (such as a proposed or final rule notice) and then to identify the supporting information associated with each Federal Register notice.

One possible way to create a system that accommodates varied agency use of dockets might be to create a structure so that information in the "docket detail" is general enough to apply to any and all Federal Register notices that might be filed in connection with a rulemaking. Such a docket detail probably should include a paragraph describing the activity that the docket supports. In addition, the docket would include nested "sub- 
domains" for each Federal Register notice associated with the docket. Some of the information in the docket system - such as whether a rule is economically significant and requires OMB review - would be placed in the Federal Register notice sub-domain for the proposed or final rule, not in the overall docket detail itself. This is important because fields of data do sometimes change during the rulemaking process. For example, a proposed rule might not initially be considered economically significant, but changes made to it may make it more costly, making the final rule economically significant under the definition in Executive Order 12866 and the Unfunded Mandates Reform Act.

\section{Recommendation: The FDMS should be designed so that information associated with individual Federal Register documents filed during a rulemaking can be included in the appropriate dockets and distinguished from information that applies across the board to the entire rulemaking.}

Contemplating subdomains for each Federal Register notices highlights another important issue: the need for consistent categories to organize and categorize Federal Register notices. One important decision will be how to distinguish between "rule" and "non-rule" Federal Register notices. For example, some agencies may open dockets in connection with studies or non-binding guidance documents in addition to rulemakings. These non-rule proceedings should be kept distinct from rulemakings, but sometimes the distinction will not be known until later in the process. An agency may open a docket thinking it will create a new rule, but later may decide only to issue a non-binding guidance document instead. 
Even for those Federal Register notices associated just with rulemaking, there is a need for consistency, both within and across agencies, in how to code the associated notices. Some categories seem to be places to start:

- ANPRM

- NPRM

- Supplemental NPRM

- Request for Comments

- Direct Final Rule

- Final Rule

- Correction/Technical Amendment

- Unified Agenda Notice or Entry

- Other (perhaps with a box allowing agency to enter a description)

Recommendation: The FDMS should make use of consistent coding of Federal Register documents, both across different rulemakings in the same agency as well as across different agencies.

\section{Data Fields for the Online Docket System}

Realizing the docket system's potential for improving scholarly and public understanding of the rulemaking process rests both upon the data within each individual docket and the ability to search and organize that data. We turn next to issues related to 
developing a complete set of the data fields for each docket. In Part III, we address issues about searching and downloading.

Including complete and appropriate data will not only facilitate scholarly research, but will also be useful to the broader public. The more complete the information in electronic dockets, the greater the likely contribution electronic dockets will make to the quality of public discourse on regulatory issues. Electronic dockets can help inform members of the public about proposed regulations and their impacts, but their impact will depend on having information in these dockets that is useful, complete, consistent, and easy to find.

The starting point for data to include in each regulatory docket should be those data that are already reported by agencies in the rulemaking process. This includes data that agencies submit to (1) the Office of the Federal Register for notices of proposed and final rulemakings, (2) the Regulatory Information Service Center for use in the Unified Agenda, and (3) the Office of Management and Budget for all significant proposed rules. (Table 1 lists the data included in each of these three categories.) It also includes information OMB already makes available in association with its review of each proposed rule. Maintaining these existing data within the new online docket system will not only serve the principle of consistency, but could also facilitate future development of agency reporting practices that avoid the duplication Table 1 shows exists in the current system.

\author{
Recommendation: The FDMS should contain all the unique data that \\ currently exist in the reports each agency already routinely submits to the
}


Office of the Federal Register, the Regulatory Information Service Center, and the Office of Management and Budget.

The data listed in Table 1 represent the minimum data reported by each agency for every rule (or in the case of the data submitted to OMB, for every "significant" rule). Many agencies provide the public with still more information through their existing, agency-specific dockets. Table 2 gives examples of such data for the Department of Transportation (DOT) and the Environmental Protection Agency (EPA). The movement to a uniform, government-wide docketing system should not result in the loss of any information currently being made available by individual agencies, so at a minimum the new government-wide docket system should include the data fields shown in Table 2. Most of the relevant data are relatively simple to gather and can be of great use both to the general public and to scholars who study rulemaking.

Recommendation: If it has not already done so, the eRulemaking Initiative should ask participating agencies to submit a list of data fields currently contained in their agency-specific dockets, or otherwise conduct a survey of the data fields in existing agency dockets.

Recommendation: Moving to the new FDMS should result in no loss of information to the public. The new system should require agencies to submit information for all the data fields that are already found in regulatory agencies' existing dockets. 
In addition to the data already contained in existing regulatory filings and agency dockets, we believe there are several new data elements that would be easily added to the new online docket system and should be made available to the user for every docket. These additional data elements include:

- The number of documents in the docket.

- The number of Federal Register documents in the docket.

- The number of public comments in the docket.

- The number of agency documents in the docket.

- The file size of the docket as a whole.

- A sortable (by author, title, and date) table of contents linking to individual documents and indicating their file size.

We anticipate that these additional elements, which could be added using automated functions, will help greatly in the organization and usefulness of the online docket system.

Recommendation: Each docket in the FDMS should contain basic summary data, such as the number of documents or comments filed, that could easily be added to the new online docket system in an early stage of its development.

Finally, to enhance researchers' ability to study the regulatory process and the public's ability to understand it, we believe that additional fields of data eventually 
should be added to the FDMS that are not currently reported by agencies in their docket systems. Although developing protocols for inclusion of some of these data will involve a longer-term effort, we hope that the work of the eRulemaking Initiative will establish a process for the future enhancement of the online docket system that can include consideration of additional data fields. Table 3 , while neither definitive nor complete, simply illustrates some of the possible types of information that could be added to the online docket system in the future.

Recommendation: Although the new online docket system should be designed at the outset to include all the data fields contained in existing docket systems, the system must have the capacity to evolve and have new data fields added that will improve both researchers' and the public's ability to understand agency rulemaking. The eRulemaking Initiative should avoid setting unnecessarily modest longer-term goals.

We recognize that including all of the fields we have suggested will not be a simple task. Thus, the first step should be to incorporate data already reported by agencies. The movement to a government-wide online docketing system, however, presents a significant opportunity for enhancing the current system of rulemaking reporting. Serious consideration needs to be given to the precise data fields to include in the FDMS. 


\section{Search and Download Capabilities}

For researchers, one of the most exciting aspects of the pending government-wide docket management system is its potential to transform the scope and method of the study of rulemaking. By making it possible for researchers to access and retrieve large numbers of agency records electronically, the system promises to bring us to the cusp of a new era in understanding both the management of rulemaking and the public's participation in this important mode of policymaking. These prospective benefits, however, will only be fully realized if the system is designed to facilitate particular kinds of searches and downloads.

Historically, research on rulemaking has usually been oriented around the study of a single rule or a small number of rules. Such intensive case study approaches are certainly of great value, and this kind of research is likely to (and should) continue to be done in the years ahead. Another important approach to research, however, has been for the most part been infeasible in the era of paper dockets, namely studies that include a large number of rulemakings. Such "large-N" studies can significantly add to our knowledge of rulemaking by helping illuminate general patterns in rulemaking, thus complementing the detailed information provided by case studies.

How specifically can the docket management system open the door up to large-N research and all of the benefits that come from this mode of inquiry? Right now, information about a large number of rulemakings can only be assembled by visiting a wide variety of online sources or the physical docket rooms in Washington, D.C. that remain to this day the sole depository of documents for many rulemakings. The FDMS 
will make a major step forward by serving as a central clearinghouse for locating and piecing together the official written records of rulemakings conducted by agencies from across the federal government.

The advantages of the government-wide online docket system for scholarly research will be still further strengthened if two elements are built into it. First, the new docket system should allow users to search for dockets or documents with user-defined search terms of any data field or combination of fields. Second, the new docket system should allow users to download a large number of documents obtained through their searches.

The first element is the capacity to search for rulemakings according to particularly broad search criteria. For many users of the system, several relatively narrow search criteria are likely to suffice. These criteria might include docket numbers, keywords, and Federal Register citations. For researchers interested in breaking new ground in the study of rulemaking, the assembly of information for large samples of rulemakings necessitates searches that cast wide nets across time and jurisdiction or issue space. For example, a researcher might seek to identify the dockets that go along with all of the rulemakings that were completed by the Environmental Protection Agency over the past five years. Another researcher might want to track down the dockets for all of the rulemakings that were open for public comment during the first six months of 2004. The general point is that the system would best facilitate research on rulemaking if a broad range of search criteria such as the following were present:

- search by specific date or date range

- search by agency 
- search by specific editions of the Unified Agenda

- search by stage in the rulemaking process

- search by a combination of these criteria

\section{Recommendation: Flexibility should be the guiding principle when it comes to searching capabilities. The FDMS should permit users to generate their own searches of any data field or combination of fields.}

In addition to accepting user-defined searches, the new docket system also must enable users to transfer information off the system to the researchers themselves. This transferred information can then be formatted and organized in ways that are directly amenable to data analysis and interpretation. Thus, a second key element of the system is the capacity to download large numbers of documents and even entire dockets in a transparent and useful way. Since all of the data in the FDMS will already be available to the public and are subject to FOIA, building a flexible download capability is consistent with current E-FOIA requirements and should actually save agencies the burden of having to respond to FOIA requests.

Recommendation: The FDMS should enable the user to download any and all data or documents retrieved through the system's search engine.

The needs of the research community, as one of a variety of communities with a stake in the development of the government-wide online docket system, are likely to 
dovetail in important ways with the eRulemaking Initiative's goal of making the regulatory process more transparent. For the research community, the FDMS promises not only to make existing modes of research far more efficient, but also to make possible underutilized modes of inquiry that can enhance our understanding of the management of and public involvement in the rulemaking process. This possibility, however, can only be fully achieved if the FDMS is designed to facilitate searches and downloads that are broadly defined across time and space, rather than limited to a handful of very specific criteria and pieces of information.

\section{Conclusion}

The creation of an online docket system has important implications both for academic researchers and anyone interested in better understanding government regulation. The principles we have enunciated will not require any dramatic changes to the regulatory process, nor even much additional commitment of resources. But we believe following these recommendations will help significantly advance the Administration's laudable goal of making it easier for the public to understand and participate in the rulemaking process. 


\section{Table 1}

Currently Submitted Data Fields for Rulemaking Proceedings

\begin{tabular}{|c|c|c|}
\hline $\begin{array}{l}\text { Data Submitted to } \\
\text { the Office of the } \\
\text { Federal Register }\end{array}$ & $\begin{array}{l}\text { Data Submitted to the } \\
\text { Regulatory Information } \\
\text { Service Center }\end{array}$ & $\begin{array}{l}\text { Data Submitted to the } \\
\text { Office of Management } \\
\text { and Budget }\end{array}$ \\
\hline $\begin{array}{ll}\text { - } & \text { Name of Rule } \\
\text { - } & \text { Agency } \\
\text { - } & \text { Department (if any) } \\
\text { - } & \text { CFR Volume } \\
\text { - } & \text { Date } \\
\text { - } & \text { rules) of NPRM (for final } \\
\text { - } & \text { Effective Date (for final } \\
\text { rules) } \\
\text { - Whether it is a direct or } \\
\text { interim final rule } \\
\text { - End of comment period } \\
\text { (for NPRMs) } \\
\text { RIN }\end{array}$ & 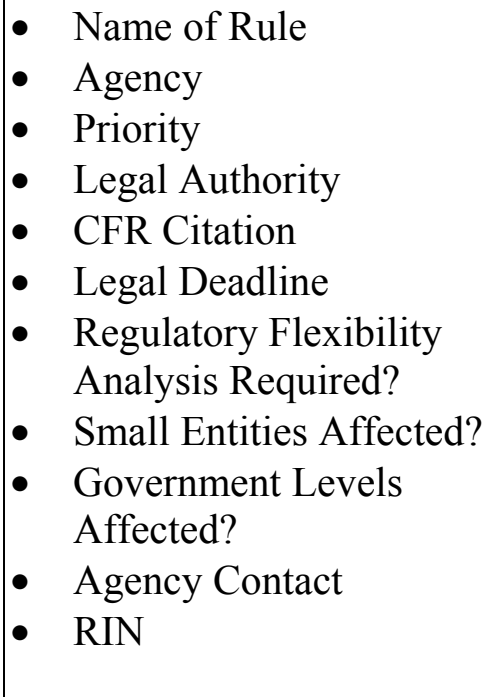 & $\begin{array}{l}\text { - } \\
\text { - } \text { Agency of Rule } \\
\text { - Legal Deadline } \\
\text { - } \quad \text { Is Deadline Statutory or } \\
\text { Judicial? } \\
\text { - Stage of Development } \\
\text { - Is rule economically } \\
\text { significant under E.O. } \\
\text { 12866? } \\
\text { - Is rule an Unfunded } \\
\text { Mandate under 2 U.S.C. } \\
\text { 1532? } \\
\text { - Agency Contact }\end{array}$ \\
\hline
\end{tabular}


Table 2

Currently Reported Data Fields in DOT and EPA Dockets

\begin{tabular}{|c|c|}
\hline \multicolumn{2}{|c|}{ Department of Transportation } \\
\hline Data for Docket as a Whole & Data Specific to Each Docket Document \\
\hline $\begin{array}{ll}\text { - } & \text { Category (e.g. Rulemaking) } \\
\text { - } & \text { Docket Status } \\
\text { - } & \text { Directive) } \\
\text { - } & \text { Docket Subject } \\
\text { - } & \text { Data Entry Date } \\
\text { - } & \text { RIN Number } \\
\text { - } & \text { Action Office } \\
\text { - } & \text { Action Sought } \\
\text { - } & \text { Docket Parties } \\
\text { - } & \text { Statutory Deadline } \\
\text { - } & \text { Close of Comment Period } \\
\text { - } & \text { Last Update } \\
\text { - } & \text { Date Docket is Closed } \\
\text { - } & \text { Statutory Cite } \\
\text { - } & \text { Number of Documents in Docket } \\
\text { - } & \text { Statutory or Judicial Requirement } \\
\text { - } & \text { CFR Citation } \\
\text { - } & \text { Docket Attributes } \\
\text { - } & \text { Docket Abstract }\end{array}$ & $\begin{array}{l}\text { - } \text { Data Entry Date } \\
\text { - } \text { Document Title } \\
\text { - Next Due Date } \\
\text { - Document Date } \\
\text { - Filing Date } \\
\text { - Answer Date } \\
\text { - Reply Date } \\
\text { - Next Due Item } \\
\text { - Federal Register Citation } \\
\text { - Federal Register Publication Date } \\
\text { - Submitter } \\
\text { - Submitter's Representative } \\
\text { - Service Date } \\
\text { - Effective Date } \\
\text { - Assigned Document Numbers } \\
\text { - Related Reply to Document \#'s } \\
\text { - Pages } \\
\text { - Submissions } \\
\text { - Abstract } \\
\text { - File Size }\end{array}$ \\
\hline \multicolumn{2}{|c|}{ Environmental Protection Agency } \\
\hline Data for Docket as a Whole* & Data Specific to Each Docket Document \\
\hline $\begin{array}{l}\text { - } \text { Docket ID } \\
\text { - } \text { Phase } \\
\text { - Short Title } \\
\text { - } \text { Title } \\
\text { - Legacy Identifier } \\
\text { - } \quad \text { Description } \\
\text { - Type } \\
\text { - Comment Period Ends } \\
\text { *With links to Related Dockets, Contacts, } \\
\text { Organizations, CFR citations, Acts, } \\
\text { Chemicals, Goals, Documents and all of } \\
\text { the above. }\end{array}$ & $\begin{array}{ll}\text { - } & \text { Document ID } \\
\text { - } & \text { Docket ID } \\
\text { - } & \text { Title } \\
\text { - } & \text { Description } \\
\text { - } & \text { Type, } \\
\text { - } & \text { Author Date } \\
\text { - } & \text { Effective Date } \\
\text { - } & \text { Page Count } \\
\text { - } & \text { Phase } \\
\text { - } & \text { Media } \\
\text { - } & \text { Restricted Viewing }\end{array}$ \\
\hline
\end{tabular}




\section{Table 3}

Data Fields to Consider Adding to the Docket System Over the Longer Term

- All associated Federal Register notices (from earlier, related rulemakings through to ANPRMs)

- Pre- and Post-NPRM consultations with outside groups such as advisory committees or stakeholder meetings

- Whether Negotiated Rulemaking was used

- Associated information collections under Paperwork Reduction Act and their burden hours

- Word count of Regulatory text

- Word count of Preamble

- Length of time for OIRA review (for significant rules)

- Whether OIRA recommended changes to the rule

- Summary of economic data on the rule, such as:

- Total Benefits (a range if appropriate)

- Total Costs (a range if appropriate)

- Timing of benefits and costs

- Discount Rate Used

- Value of statistical life or life-year used (if appropriate) 